\title{
I tanmateix es mou! La relativitat del moviment a 2n d'ESO
}

Esperança Carrió (e.carrio296@gmail.com) Doctora en farmàcia per la Universitat de Barcelona (UB). Màster en Professorat d'ESO i Batxillerat a la Universitat Autònoma de Barcelona (UAB).

Roser Pintó Casulleras (roser.pinto@uab.cat) Professora emèrita de la Universitat Autònoma de Barcelona (UAB). Centre de Recerca per a l'Educació Científica i Matemàtica (CRECIM).

És impossible definir el moviment sense un sistema de referència (SR). En la nostra recerca, havent recollit les respostes d'una pregunta d'examen de les tres línies de $2 n$ d'ESO de I'INS Eugeni d'Ors de L'Hospitalet del Llobregat (Barcelona) (en total 87 alumnes), hem observat que els alumnes que han estat capaços de concretar un SR argumenten de manera més madura (especificant un canvi de posició respecte al punt de referència) que els que no han concretat el SR. Els estudiants no estan acostumats a descriure moviments, menys si és des d'un SR, i molt menys si és des d'un SR en moviment. Es va comprovar que s'aconsegueixen més èxits en les respostes dels alumnes sobre moviment si es fa servir la construcció: Es mou $M$ respecte $R$ ?, on $M$ és el mòbil i $R$ és la referència. Si $M$ canvia de posició respecte $R$, hi ha moviment; en canvi, si $M$ no canvia de posició respecte $R$, no hi ha moviment.

Paraules clau: moviment, relativitat, sistema de referència, canvi de posició, 2n ESO.

It is impossible to define motion without using a reference system (RS). In our research, we collected and analyzed all the information given by 87 students answering an exam question about motion. The students were from the three groups of 2nd year of secondary school Eugeni d'Ors (L'Hospitalet del Llobregat, Barcelona). We observed that students who were able to set a RS, they could better and more maturely argue about motion (specifying a change of position in relation to the point taken as reference), compared to the students who did not concrete a RS. Students are not used to describe movements, not from a $R S$, and a lot less from a moving $R S$. It has been proved that the best sentence construction to be used by the teacher when facing motion learning is: Is $M$ moving in relation to $R$ ?, where $M$ is the moving object and $R$ is the reference. If $M$ changes position in relation to $R$, then there is motion; otherwise, if $M$ does not change position in relation to $R$, it means there is no motion.

Keywords: motion, relativity, reference system, change of position, 2nd ESO

\section{INTRODUCCIÓ}

Arran de la realització de les pràctiques del Màster de Professorat d'ESO i Batxillerat a l'INS Eugeni d'Ors de L'Hospitalet del Llobregat (Barcelona) vam preparar una unitat didàctica (UD) que porta per títol Ens movem per la ciutat i que treballa el moviment en física a 2n d'ESO (Ballarin i Carrió, 2015). Un dels primers punts de la UD era definir què és el moviment i què vol dir que una cosa es mou, així com la idea de relativitat (o sigui, la dependència de qualsevol moviment a un sistema de referència a partir del qual es descriu aquest moviment). Treballar aquests conceptes amb els alumnes de $2 \mathrm{n}$ d'ESO de l'INS Eugeni d'Ors va ser tot un repte i ens vam adonar de les dificultats dels alumnes a l'hora d'argumentar si un cos es mou o no. Vam creure interessant explorar quins havien estat els seus patrons de raonament sobre el concepte de moviment en les respostes de l'examen. Si aconseguíem entendre com els alumnes argumenten el fet de moure's, tal 
vegada en posteriors intervencions podrem ajudarlos a comprendre millor la relativitat del moviment $\mathrm{i}$ la seva concepció física.

Dels autors que vam prendre com a marc conceptual $\mathrm{i}$ antecedents del nostre treball en destaquem tres: Bliss (2008; Bliss i Ogborn, 1994), Castells (1989) i Monereo (1995; Monereo et al., 2001; Pozo et al., 2001). De Bliss i Castells en vam adaptar el mètode de recollida i anàlisi de les dades (ús de xarxes sistèmiques $i$ anàlisi qualitatiu de les respostes), ja que les seves recerques s'assemblen molt a la nostra, tot i que en elles es tracten les causes del moviment (dinàmica) i no la definició de moviment (concepció). La recerca de Castells pren el concepte de sistema de referència com a base per a treballar el concepte de moviment, i és que, de fet, d'estudis sobre la definició del moviment en ciència hi ha certament molt poca literatura. Bliss i els seus col-laboradors desenvolupen l'anomenada Commonsense Theory of Motion (teoria del sentit comú del moviment), i entenen que la construcció del coneixement es fa a partir de la simple reproducció de la realitat pròpia, de dir i creure les coses tal com són des del propi punt de vista, o sigui, que els alumnes utilitzen els seus propis coneixements quotidians per a explicar el món físic.

De Monereo en vam captar la proposta de modelatge metacognitiu, que aprofitem per intentar explicar com els alumnes fan el procés d'entesa del concepte del moviment i de la seva relativitat (anàlisi dels patrons de raonament $\mathrm{i}$ aprenentatge del concepte de moviment). El modelatge metacognitiu de Monereo es refereix a l'explicitació del professor (què pensa i com raona les seves decisions) a l'hora de resoldre un problema o d'aprendre un contingut. Per als alumnes de $2 n$ d'ESO, i segons el currículum de la Generalitat de Catalunya, el moviment en física és el primer tema de Física que veuen en la seva vida d'estudiants. Monereo subratlla que és oportú, sobretot, portar a terme un modelat quan es comencen tasques complexes que són noves o desconegudes per als alumnes. El modelatge metacognitiu afavoreix, per una banda, que els alumnes comprenguin la importància de la presa de decisions en el procés (encara que sigui en la definició de si un cos es mou o no), i per una altra, la flexibilitat dels processos (poques vegades hi ha només una manera de fer les coses) i l'ús del vocabulari associat a l'àmbit d'estudi.

Llavors, el present treball planteja els següents objectius: (1) analitzar els patrons de raonament dels alumnes de $2 \mathrm{n}$ d'ESO per a explicar què significa estar en moviment, i, en base a l'estudi d'aquests patrons, (2) fer una anàlisi d'un canvi d'estratègia en presentar la relativitat del moviment en la física de $2 \mathrm{n}$ d'ESO, comparant les intervencions entre els grups $\mathrm{B}$ i C.

\section{METODOLOGIA}

Un total de 87 alumnes de $2 n$ d'ESO de l'INS Eugeni d'Ors de L'Hospitalet del Llobregat han participat en aquesta recerca. D'aquests, 28 són del grup A, 28 del B i 31 del C. De cada grup hem analitzat l'apartat de l'examen (o activitat d'aplicació de la UD) on es demana als alumnes que expliquin per què un cos es mou o no. Amb aquestes respostes, examinem el tipus de raonament sobre la concepció del moviment que fan els alumnes de $2 \mathrm{n}$ d'ESO de manera individual $\mathrm{i}$ comparem les respostes dels tres grups classe. A més, fem el seguiment del canvi d'estratègia de les professores del grup $C$ respecte el B. De fet, el grup B va ser el nostre conillet d'Índies. Va ser el primer grup amb el qual aplicàvem la UD Ens movem per la ciutat. El B és un grup molt callat, d'actitud extremadament passiva, que costa fer treballar, i de rendiment acadèmic baix. Per a explicar el concepte de moviment amb el B vam fer representacions teatralitzades a classe, vam fer anàlisis de fotografies -la d'un autobús a una parada, seguint la idea de Bliss (2008) i les vinyetes de còmicdemanant què es movia respecte què o qui, però no vam insistir en el tipus de vocabulari ni en la manera d'expressar el moviment (pensàvem que quedava implícit en el tipus de pregunta, de l'estil "Es mou M respecte $R$ ?', llavors els alumnes havien d'aprendre que $M$ es movia o no prenent $R$ com a referència). Però això per als alumnes no era tan obvi, i es va canviar de tàctica en el grup $\mathrm{C}$. Des del primer moment, treballavem amb l'examen (o activitat d'aplicació) en ment, i sabíem molt bé què demanaríem. Sempre escrivíem les respostes a la pissarra, fent èmfasi en la frase "canvi de posició respecte a", i durant dos dies vam demanar, al principi de classe, una o dues preguntes per escrit per regular l'aprenentatge del concepte i del vocabulari. Amb el fet d'escriure sempre les respostes a la pissarra i fer les correccions per escrit a les preguntes de l'inici de classe, estàvem introduint una estratègia de metacognició: "mira com jo responc i tu ho has de fer igual". Val a dir que el grup $C$ és un grup de rendiment acadèmic mixt, més baix que $A$ però més alt que $B$. En el grup $C$ els alumnes són moguts i xerraires, però aquest caràcter inquiet no és sempre negatiu. Si els interessa el que està explicant la professora, fan silenci quan toca i fan preguntes curioses relacionades amb el tema. 
Les preguntes per a cada grup són les de la taula 1. Les preguntes 3 i 4 són les que presenten més complicació de resposta. La 3 perquè el SR és mòbil (la noia), i la 4 perquè abans de contestar s'ha d'haver entès que el metro estava aturat.

\begin{tabular}{|l|l|}
\hline Grup & Pregunta amb context sobre el concepte de moviment \\
\hline A & $\begin{array}{l}\text { Una persona està observant el firmament i diu: "Durant l'es- } \\
\text { tona que he estat aquí, la Lluna s'ha mogut molt." Al mateix } \\
\text { temps, un astronauta que és a la Lluna i també contempla } \\
\text { el cel diu al seu company: "T'has fitxat com ha canviat de } \\
\text { posició, la Terra?". Justifica quina de les dues persones té } \\
\text { raó. }\end{array}$ \\
\hline B i C & $\begin{array}{l}\text { El Joel entra al vagó del metro i s'asseu. Contesta les pre- } \\
\text { guntes: }\end{array}$ \\
& $\begin{array}{l}\text { 1) Respecte a la persona que està asseguda al seu costat, } \\
\text { el Joel s'està movent? Per què? } \\
\text { 2) El Joel es mou respecte al conductor del metro? Per què? } \\
\text { 3) Una noia s'aixeca i es dirigeix a la porta per sortir a la } \\
\text { següent parada. El Joel es mou respecte a aquesta noia? } \\
\text { Per què? } \\
\text { 4) El metro s'atura en una parada. El Joel es mou respecte } \\
\text { l'andana? I l'andana respecte el Joel? }\end{array}$ \\
\hline
\end{tabular}

Taula 1. Preguntes de l'examen de cada grup classe de $2 n$ d'ESO (A, B i C) que ens han proporcionat les respostes o dades d'anàlisi d'aquesta recerca.

A l'hora d'analitzar les respostes hem fet ús d'una xarxa sistèmica basada en les respostes dels alumnes. Els comptatges de cada categoria s'han dut a terme en un full de càlcul Excel ${ }^{\circledR}$. La xarxa sistèmica que hem usat en aquesta recerca refereix la dimensió argumentativa de la relativitat del moviment i, més concretament, de l'afirmació o no per part dels estudiants de si és o no necessària la identificació d'un SR per a explicar que un cos es mou o està quiet (Bliss et al., 1983; Castells, 1989).

\section{RESULTATS}

En base a les respostes dels alumnes de tots els grups, i per a les dues tipologies de pregunta, hem dissenyat la xarxa de la figura 1. De la categorització de la xarxa n'extraiem set tipologies de resposta que, ordenades de dalt a baix, van de menys a més elaborades. La categoria CPOS és el tipus d'argumentació més madura i coherent amb el model de resposta que nosaltres esperàvem. Els resultats específics per a cada grup i per a cada pregunta es resumeixen a la taula 2 . A la taula 2 s'afegeix una columna que especifica el percentatge de respostes correctes al marge de la categoria argumentativa. Aquest percentatge està calculat sobre el total d'alumnes que han contestat la pregunta, i no del total d'alumnes de la classe (exclosos els NR/ND).
Amb aquesta dada volem establir una relació entre la correcció de la resposta i el tipus de resposta dels alumnes. De la pregunta 4 dels grups B i C n'hem valorat les dues parts que té (4a: el Joel respecte l'andana, i 4b: l'andana respecte el Joel).

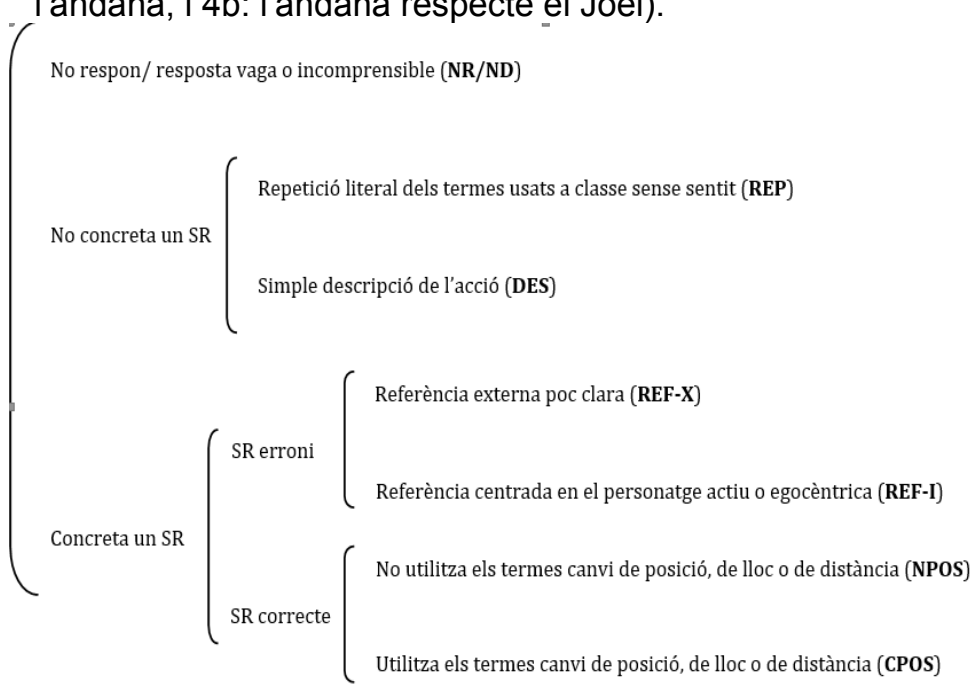

Figura 1. Xarxa de la dimensió argumentativa sobre la relativitat del moviment. Les abreviacions que apareixen entre parèntesi seran les que farem servir per a l'anàlisi de les dades per categories i per grups.

De la taula 2 observem que els alumnes del grup A responen la seva pregunta amb arguments majoritàriament basats en la repetició dels termes que s'han exposat a classe (REP). En canvi, els alumnes del grup $\mathrm{B}$ responen majoritàriament amb la simple descripció de l'acció dels personatges de la pregunta (DES), i els alumnes del grup $\mathrm{C}$ utilitzen les paraules "canvi de posició, de lloc o de distància" (CPOS) a l'hora d'argumentar el moviment en la pregunta.

Pel que fa a l'aplicació del canvi d'estratègia per al grup $C$ respecte el grup $B$ s'observa un augment de la correcció de les respostes i, a més, un increment dels estudiants que utilitzen arguments més madurs. La pregunta 3 és la que presenta més complicacions, un percentatge menor de correcció $i$ una dificultat més elevada de concretar el SR (la tendència és la referenciació egocèntrica, que és la d'elecció en cas de dubte per part dels estudiants).

\section{DISCUSSIÓ DELS RESULTATS I CON- CLUSIONS}

Tres alumnes del grup A han encertat el SR, tot $\mathrm{i}$ que més del $60 \%$ dels que contesten han escrit correctament que les dues persones tenien raó en les 
afirmacions de la pregunta. La resposta majoritària de l'A ha estat l'argument de què la Lluna gira al voltant de la Terra, i la Terra al voltant del Sol, sense identificar la dependència del SR concret per a cada cas. Fer servir aquest argument és repetir una idea que s'ha dit a classe sense haver entès la necessitat d'establir el punt de referència. És un dels perills de l'aplicació del context de la història de la ciència sense un reforç de raonament conjunt de la professora $\mathrm{amb}$ el grup classe (anar més enllà de l'anècdota històrica i de l'interès cosmològic divulgatiu). Tanmateix, que més del $60 \%$ de les respostes dels alumnes siguin correctes, tot i no fer servir el SR per a argumentar, també pot dir una altra cosa: els alumnes ho veuen, ho entenen, però no ho saben escriure o raonar. Preguntes com les que considerem per aquesta recerca són, per als alumnes, tractades com a difícils.

Aquesta dificultat lingüística també s'observa en el grup $B$. Les respostes majoritàries eren de simple descripció de l'acció, sense concretar un SR, sinó imaginant la seqüència i escrivint què hi veien. Als alumnes del $\mathrm{B}$ els costa prendre de punt de referència un personatge extern al principal o a ells mateixos, per això han tingut més errors en contestar les preguntes 2 i 4b. La referenciació egocèntrica (REFI) és un dels errors més habituals quan aprenem a explicar el moviment. Els alumnes del B els ha faltat un pas més per a arribar a fer una argumentació més madura, segurament per no voler-los donar una pauta tan estricta o tancada de resposta.

D'alguna manera s'ha aconseguit: cap alumne repeteix les paraules de la professora, de les idees de classe, que van ser diverses, amb representacions teatrals, de diàleg, d'interpretació de fotografies. Però no es va acordar cap resposta model. Potser per això cap alumne tampoc utilitza les paraules "canvi de posició, de lloc o de distància" per a raonar les respostes, però sí que, en la pregunta 1, 2 de 12 alumnes aconsegueixen concretar correctament la referència i explicar per què es mou sense explicitar la paraula "canvi". A l'hora de treballar el concepte de moviment amb el grup $C$ es va canviar d'estratègia d'ensenyament, fent servir el modelatge metacognitiu proposat per Monereo, de l'estil: "per a contestar bé aquesta pregunta, heu de posar això", o sigui, "per dir si un cos es mou, heu de referir que hi ha un canvi de posició respecte allò que prenem de referència".

El grup amb el percentatge de respostes correctes més elevat és el C. El 100\% dels alumnes que responen la primera pregunta ho fan correctament, $\mathrm{i}$ majoritàriament són alumnes que argumenten fent ús de les paraules "canvi de posició, de lloc o de distància" (CPOS). Hi ha una relació estreta entre percentatges alts de resposta correcta i d'argumentació CPOS. En general, els alumnes del grup $\mathrm{C}$ són capaços d'identificar millor el punt de referència del moviment, excepte en la pregunta 3. La professora del $C$ va insistir molt en la resposta model al tipus de pregunta de l'examen. Això ha donat molt bons resultats en les comparacions argumentatives amb els altres grups, però té un perill. El perill són els 2-3 alumnes que han respost repetint exactament les paraules "canvi de posició", però sense explicitar cap SR. Queda clar, però, amb els comptatges de les categories de la xarxa, que als alumnes els ajuda a argumentar millor el "canvi de posició de respecte a" per a identificar el SR i, per tant, contestar correctament la pregunta. També els ajuda en les preguntes 3 i 4 , que presentaven més dificultat. Per a l'última pregunta, tant en el cas del grup $\mathrm{C}$ com en el $\mathrm{B}$, hi ha pocs alumnes que la contestin però, si ho fan, ho fan millor que a les altres preguntes (major percentatge d'encerts).

\begin{tabular}{|c|c|c|c|c|c|c|c|c|}
\hline GRUP CLASSE & \multirow{2}{*}{$\begin{array}{c}\text { \% RESPOSTES } \\
\text { IPREGUNTA }\end{array}$} & \multicolumn{6}{|c|}{ Número d'alumnes (percentatge d'alumnes respecte el total) per cada categoria } \\
\cline { 5 - 9 } & CORRECTES & NR/ND & REP & DES & REF-X & REF-I & NPOS & CPOS \\
\hline A & 63.6 & $11(39 \%)$ & $8(29 \%)$ & $2(7 \%)$ & $3(11 \%)$ & $1(4 \%)$ & $2(7 \%)$ & $1(4 \%)$ \\
\hline B1 & 66.7 & $16(57 \%)$ & $0(0 \%)$ & $3(11 \%)$ & $2(7 \%)$ & $5(18 \%)$ & $2(7 \%)$ & $0(0 \%)$ \\
\hline B2 & 36.4 & $19(68 \%)$ & $0(0 \%)$ & $2(7 \%)$ & $4(14 \%)$ & $3(11 \%)$ & $0(0 \%)$ & $0(0 \%)$ \\
\hline B3 & 41.7 & $18(64 \%)$ & $0(0 \%)$ & $3(11 \%)$ & $0(0 \%)$ & $5(18 \%)$ & $2(7 \%)$ & $0(0 \%)$ \\
\hline B4a & 36.7 & $18(64 \%)$ & $0(0 \%)$ & $6(21 \%)$ & $2(7 \%)$ & $1(4 \%)$ & $1(4 \%)$ & $0(0 \%)$ \\
\hline B4b & 77.8 & $21(75 \%)$ & $0(0 \%)$ & $6(21 \%)$ & $0(0 \%)$ & $0(0 \%)$ & $1(4 \%)$ & $0(0 \%)$ \\
\hline C1 & 100 & $18(58 \%)$ & $3(10 \%)$ & $2(6 \%)$ & $0(0 \%)$ & $2(6 \%)$ & $0(0 \%)$ & $6(19 \%)$ \\
\hline C2 & 84.6 & $19(61 \%)$ & $3(10 \%)$ & $1(3 \%)$ & $0(0 \%)$ & $2(6 \%)$ & $1(3 \%)$ & $5(16 \%)$ \\
\hline C3 & 46.2 & $19(61 \%)$ & $2(6 \%)$ & $2(6 \%)$ & $0(0 \%)$ & $4(13 \%)$ & $0(0 \%)$ & $4(13 \%)$ \\
\hline C4a & 61.5 & $19(61 \%)$ & $3(10 \%)$ & $2(6 \%)$ & $0(0 \%)$ & $1(3 \%)$ & $0(0 \%)$ & $6(19 \%)$ \\
\hline C4b & 87.5 & $23(74 \%)$ & $2(6 \%)$ & $1(3 \%)$ & $0(0 \%)$ & $0(0 \%)$ & $1(3 \%)$ & $4(13 \%)$ \\
\hline
\end{tabular}

Taula 2. Comptatges de la tipologia de respostes per pregunta i per grup. La codificació de la columna grup té la llegenda grup i pregunta. Ex: B1 és grup B, pregunta 1 
És molt significativa en tots els grups la xifra d'alumnes que no responen o que la seva resposta és vaga o incomprensible (NR/ND); en tots els casos més de la meitat de la classe no respon o escriu només Sí o No (o qui té la raó en la pregunta del grup A) sense explicar el perquè de la seva resposta. De cada classe hi ha uns 2-3 estudiants que assisteixen diàriament a les aules d'acollida per a millorar la seva expressió en català. Probablement per a aquest últim tipus d'alumnes s'hauria de preparar un examen o activitat d'aplicació oral, o preparar-los una pauta de resposta molt ben estructurada i treballada a classe (avançant l'estratègia d'aprenentatge), de l'estil que proposem a continuació, una proposta molt semblant a la del quadern de Karplus (1972):

\section{Es mou $M$ respecte $R$ ? \\ $M$ és el mòbil \\ $R$ és la referència \\ Si $M$ canvia de posició respecte $R$, hi ha movi- ment}

Si M no canvia de posició respecte $R$, no hi ha moviment

Aquesta solució no només seria vàlida per aquells que tenen problemes de caire lingüístic, sinó també per a tots els alumnes. En la comparació dels resultats entre $\mathrm{B}$ i $\mathrm{C}$, hem vist la utilitat del modelatge estratègic en l'aprenentatge de la concepció del moviment en física. L'aplicació de l'estratègia didàctica de reforç en la pròpia definició del moviment $i$, concretament, de la seva relativitat, ha comportat millors resultats (entre un 13 i un $20 \%$ més dels alumnes, o sigui, els alumnes que sí que utilitzen la categoria CPOS en la seva argumentació).

L'únic gran inconvenient de treballar focalitzats en la consecució d'un tipus d'argument CPOS, com ho ha fet el grup $\mathrm{C}$ i que nosaltres en aquesta recerca hem considerat com a raonament més madur, és que en realitat estem treballant una construcció lingüística, i no podem saber si els alumnes han pres consciència interna del concepte de moviment. La tàctica del CPOS és parcialment memorística $\mathrm{i}$ retalla la creativitat dels estudiants.

La millora de la proposta de treball de la definició del moviment passa perquè els estudiants investiguin els seus propis dubtes de si una cosa es mou o no, amb molta oralitat per part del professor i molt qüestionament per part dels altres estudiants de la mateixa classe. El grup B d'aquest estudi, de resposta més creativa (basada en la descripció de l'acció, tot i que sovint errant la referència, que sol ser egocèntrica per falta de maduresa del concepte), ho ha treballat bé, però li ha faltat estructuració. Li ha faltat acabar les dinàmiques identificant els actors del sistema en moviment o repòs: qui es mou? Respecte de qui es mou? Qui és, llavors, la referència? Hi ha canvi de posició, de lloc o varia la distància? Les respostes a aquestes preguntes s'han d'escriure a la pissarra i esquematitzar, perquè, al cap i a la fi, estem treballant una construcció causal.

\section{AGRAIIMENTS}

Gràcies a la Glòria Borràs per a la revisió del manuscrit i per a tutoritzar el treball d'E.C. a l'Institut Eugeni d'Ors. Gràcies també a la resta de professorat $i$ a l'equip directiu del centre per acollir-nos tan bé. Les professores dels grups $\mathrm{A}$ i $\mathrm{C}$ han estat l'Estefania i la Raquel, a les quals agraïm molt sincerament la seva col-laboració. Amb el Dr. Víctor López varem compartir els inicis del treball, ens va aportar idees i finalment n'ha fet una revisió exhaustiva; per tota aquesta feinada, li expressem la nostra màxima gratitud.

\section{BIBLIOGRAFIA}

BALLARIN, R., CARRIÓ, E. (2015). Ens movem per la ciutat. Unitat didàctica sobre el moviment en física. Màster UAB. Implementada a l'INS Eugeni d'Ors, L'Hospitalet del Llobregat.

BLISS, J. (2008). Commonsense reasoning about the physical world. Studies in Science Education, 44(2): 123-155.

BLISS, J., OGBORN, J. (1994). Force and motion from the beginning. Learning and Instruction, 4: 7-25.

BLISS, J., MONK, M., OGBORN, J. (1983). Qualitative data analysis for educational research. A guide to uses of systemic networks. London: Croom Helm.

CASTELLS, M. (1989). Concepcions i raonaments en l'ús de sistemes de referència galileans. Temps d'Educació, 2.

KARPLUS, R. (dir.) (1972). Relative position and motion. Teacher's guide. SCIS. Berkeley: Universitat de Califòrnia.

MONEREO, C. (1995). Enseñar a conciencia. ¿Hacia una didáctica metacognitiva? Aula de innovación educativa, 34: 74-80

MONEREO, C., POZO, J.I., CASTELLÓ, M. (2001). La enseñanza de estrategias de aprendizaje en el contexto escolar. En: Coll, C., Palacios, J., Marchesi, A. (coord.). Psicología de la educación escolar. Madrid: Alianza Editorial.

POZO, J.I., MONEREO, C., CASTELLÓ, M. (2001). El uso estratégico del conocimiento. En: Coll, C., Palacios, J., Marchesi, A. (coord.). Psicología de la educación escolar. Madrid: Alianza Editorial. 